\title{
Effects of Wastewater Treatment Plant's Discharges on a Freshwater Ecosystem-a Case Study on the Ramalhoso River (Portugal)
}

\author{
P. Almeida • T. Albuquerque - M. Antunes $\mathbb{D} \cdot$ A. \\ Ferreira • G. Pelletier
}

Received: 28 December 2020 / Accepted: 12 April 2021

(C) The Author(s), under exclusive licence to Springer Nature Switzerland AG 2021

\begin{abstract}
Sewage discharges constitute severe stress in freshwater ecosystems. The Ramalhoso River belongs to the Tagus River watershed and was chosen for a pilot study on the impact of wastewaters discharges in a freshwater ecosystem and its ability for self-depuration. Twelve water samples were collected along the river and were georeferenced. The first point is located upstream of the first discharge point, the second one corresponding to the discharge flow, and all the other samples located downstream of secondary inflows at approximately equal distances. Three sampling campaigns were conducted during the rainy winter (January), the intermediate conditions (March), and the dry season (June). The following chemical parameters were analyzed: biochemical oxygen demand for 5 days
\end{abstract}

P. Almeida

Câmara Municipal da Guarda, Guarda, Portugal

e-mail: almeidafigueira@hotmail.com

T. Albuquerque

Instituto Politécnico de Castelo Branco | CERNAS | QRural and ICT, Universidade de Évora, Évora, Portugal

e-mail: teresal@ipcb.pt

M. Antunes $(\bowtie)$

ICT | Universidade do Minho, Braga, Portugal

e-mail: imantunes@dct.uminho.pt

\author{
A. Ferreira \\ Instituto Politécnico de Castelo Branco, Castelo Branco, Portugal \\ e-mail: amferreira@ipcb.pt \\ G. Pelletier \\ Washington State Department of Ecology, Olympia, WA, USA \\ e-mail: gregp@sccwrp.org
}

$\left(\mathrm{BOD}_{5}\right)$, dissolved oxygen concentration (DO), total phosphorus $\left(\mathrm{P}_{\text {total }}\right)$, total nitrogen $\left(\mathrm{N}_{\text {total }}\right)$, $\mathrm{pH}$, temperature, total suspended solids (TSS), microbiological parameters (MP), and flow determination. Dissolved oxygen, $\mathrm{BOD}_{5}$, and TSS were used as indicators of environmental pollution. A coupled hydrodynamic and water dispersion model simulated different pollution scenarios using the QUAL2kw software to construct a water quality model. The simulation results are consistent with field observations and demonstrate that the model has been correctly calibrated, allowing feasibility studies of different treatment schemes and the development of specific monitoring activities.

Keywords Water quality · Numerical simulation · QUAL2Kw $\cdot$ Ramalhoso River $\cdot$ Portugal

\section{Introduction}

Sewage treatment plant discharges are one of the biggest problems in developed and developing countries, contributing to an unclear and unstable aquatic ecosystem, including, but not limited to, oxygen demand and nutrient loading in the receiving basin (e.g., Albuquerque et al., 2019; Aubertheau et al., 2017; Gonzalo \& Camargo, 2013; Hilario Garcia et al., 2017; Li et al., 2016). Furthermore, sewage discharge may have a considerable impact on public health, mainly when the effluent is directly discharged into the waterline and subsequently used in human activities (Xiao et al., 2018; Zafar et al., 2017). Environmental protection from 
adverse effects of wastewater discharges and adequate management in the European Union is currently legislated under the EU Urban Wastewater Treatment Directive (European Union, 1991).

This study points to evaluate the usage of water quality models to better understand the response of a river under the influence of different loads of nutrients. The QUAL2Kw model was used in an applied survey aiming to model the Ramalhoso River's water quality. Therefore, making possible the representation of a complex set of parameters downstream the river, and the corresponding impact on water quality.

Considering that most of the chemicals are originated from urban and agricultural areas and enter the aquatic environment, mainly via urban runoff (Delhomme et al., 2008), and/or domestic and industrial wastewaters (Sousa et al., 2018), a special focus should be addressed to domestic and agricultural catchments (Tiedeken et al., 2017; Vystavna et al., 2018).

Modeling water's quality became a useful tool in determining contamination behavior and corresponding water quality impacts. Simulated scenarios allow accessing a set of possibilities and the assessment of mitigation plans in face of a contamination occurrence (Antunes et al., 2018; DiGiano \& Grayman, 2014; Henderson-Sellers, 1991). Pollution simulation is a serious issue as it has consequences for hydrological modeling and discharge predictions for environmental impact assessment (Farhadian et al., 2019; Khwairakpam et al., 2019; Tillaart et al., 2013; Whitehead et al., 2015). Modeling can be a useful management tool because models allow understanding the water body response to different pollution pressure scenarios which may assist in the decision-making process and in prosecuting the Water Framework Directive objectives.

Mathematical modeling makes it possible to estimate contamination loads in an aquatic environment (Grabiç et al., 2011; Henderson-Sellers, 1991; Jeznach et al., 2016; Lin et al., 2010), by establishing cause and effect relationships between pollution sources and water quality and simulated different aquatic response scenarios in different controlled situations. The simulation results serve as a management tool for policymakers predicting the effect of accidental releases or additional polluting loads. In the literature, various examples of QUAL2KW modeling can be found, used as a tool for simulating the water quality in rivers and catchment areas using as control parameters: biochemical oxygen demand $\left(\mathrm{BOD}_{5}\right)$, total nitrogen $\left(\mathrm{N}_{\text {total }}\right)$, total phosphorus $\left(\mathrm{P}_{\text {total }}\right)$, and chemical oxygen demand (COD) loads (Sharma \& Kansal, 2013). QUAL2KW is also widely utilized for studying water quality management strategies (e.g., Fan et al., 2009; Grabiç et al., 2011; Henderson-Sellers, 1991; Jeznach et al., 2016; Lin et al., 2010; Pelletier et al., 2006; Sharma \& Kansal, 2013; Xiaobo et al., 2008).

The Ramalhoso River watershed is in the central mainland of Portugal, in the district of Castelo Branco, covering an area of approximately $54.81 \mathrm{~km}^{2}$. The river is integrated into the Tagus River's watershed (Fig. 1).

The hydrographic network of the Ramalhoso watershed can be divided into two distinct zones: the right bank, characterized by small tributaries with a weak order of classification and by low drainage density, given the weak longitudinal slope of watercourses, and the left bank, with tributaries of a high order and high drainage density, seeping approximately $58 \%$ of the watershed area. The climate in the survey area is temperate with rainy winter and hot dry summer.

When wastewater is discharged into a water line, with biodegradable organic substances, whether of domestic or industrial origin, the action that these exert on the waterline will depend on the relationship between the volume of water and the volume of the discharge. Dilution will be the main factor that intervenes in minimizing the impact that the discharge may cause on the waterline (Albuquerque et al., 2019).

Consequently, after receiving organic pollutants, the balance between habitats is resulting in the initial disorganization followed by a post-reorganization trend. In this sense, the self-purification in watercourses can be understood as a phenomenon of ecological succession, following a systematic sequence of substitution from one community to another, until one community establishes itself in balance with the new conditions.

The objectives of monitoring water lines include the assessment of the spatial-temporal quality of inland waters and providing a survey of the priority areas for the control of water pollution. Indeed, identifying sections where the quality may be more degraded allows enabling preventive and control actions by the responsible entities to achieve the good ecological status of the waters. The monitoring of the waterline is also an evaluation mechanism, which can contribute as a basis for an action plan of the same and the surrounding areas.

The Ramalhoso River basin shows pollution issues mainly associated with organic contamination namely due to the influence of the wastewater plant's discharge. 


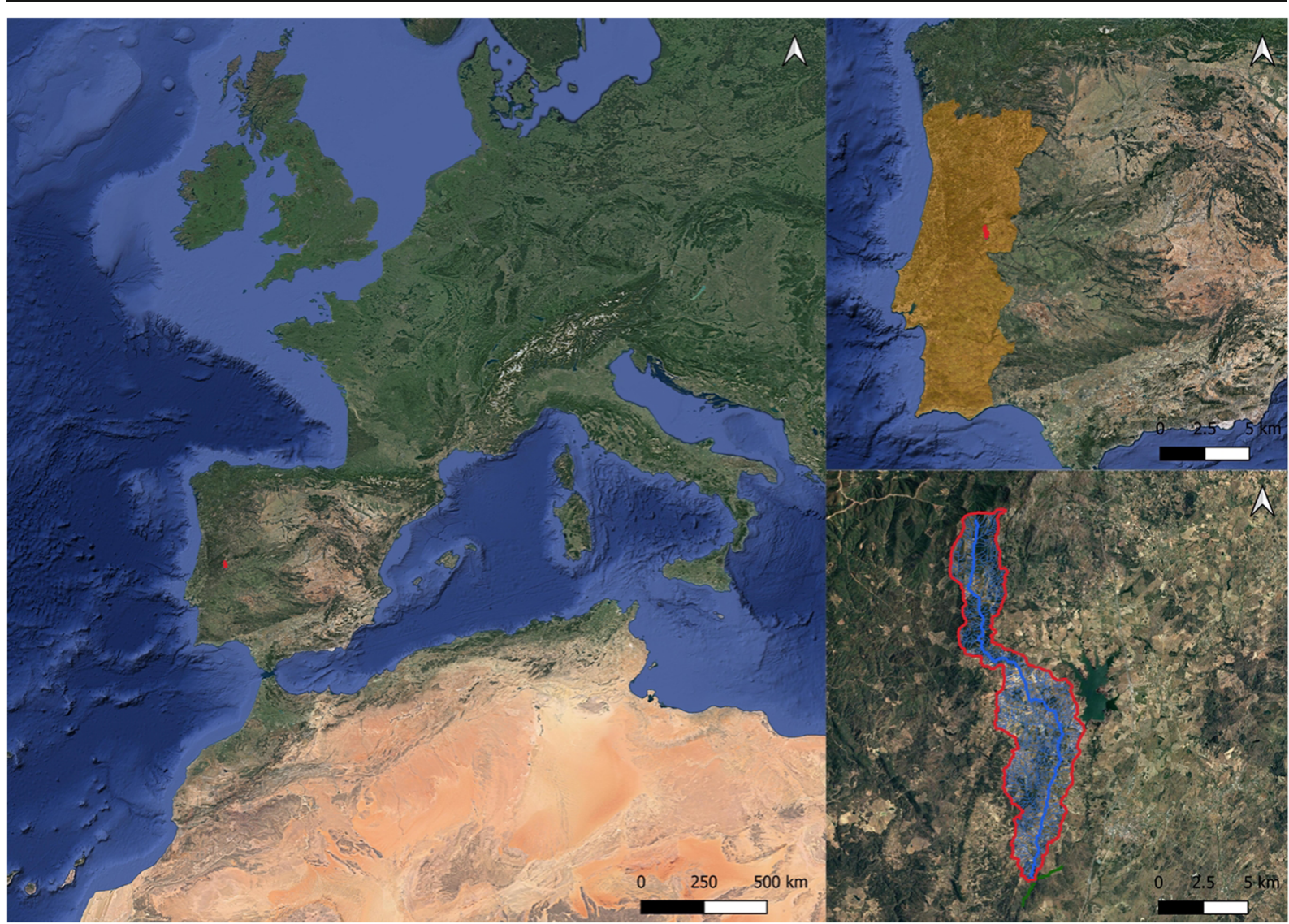

Fig. 1 Ramalhoso River Watershed location in the Castelo Branco district, Portugal

The water quality model was fairly calibrated for most of the parameters and is an important tool for water management and ecosystem monitoring.

\section{Materials and Methods}

The first step was the definition of a sampling design which, in this survey, was outlined aiming at two aspects: (1) construction of a water quality model for the Ramalho River and (2) control the water quality impact of the Ramalhoso River in the Ocreza River, considering the associated seasonality. The Ocreza River is an important tributary of the Tagus River, being an important economic and welfare source for the neighboring populations.

The sampling design includes (1) ten georeferenced samples (P1-P10) collected in the Ramalhoso River and working as input values for the water quality model computation (Ramalhoso River) and (2) two control samples (P11 and P12; Fig. 2) in the Ocreza River.
These twelve samples were collected over three different time frames: (1) wet winter (January); (2) intermediate conditions (March); and (3) dry season (June). The collected water samples were transported in polypropylene bottles (with the addition of sodium thiosulfate solution) within thermic arks to the Certified Regional Laboratory of Trás-os-Montes, Lda (Portugal).

The water parameters analyzed included biochemical oxygen demand $\left(\mathrm{BOD}_{5}\right)$, chemical oxygen demand (COD), dissolved oxygen (DO), total phosphorus $\left(\mathrm{P}_{\text {total }}\right)$, total nitrogen $\left(\mathrm{N}_{\text {total }}\right), \mathrm{pH}$, temperature, total suspended solids (TSS), and microbiological parameters (MP-fecal coliforms). Temperature, $\mathrm{pH}$, electrical conductivity, dissolved oxygen, oxi-reduction potential, total dissolved solids, and salinity were measured "in situ" using a multiparametric portable probe Hanna Instruments Model HI 9828. Total suspended solids (TSS), biochemical oxygen demand $\left(\mathrm{BOD}_{5}\right)$, chemical oxygen demand (COD), dissolved oxygen (DO), microbiological parameters (MP), total phosphorus $\left(\mathrm{P}_{\text {total }}\right)$, and total nitrogen $\left(\mathrm{N}_{\text {total }}\right)$ followed the protocol set out in Table 1 . 

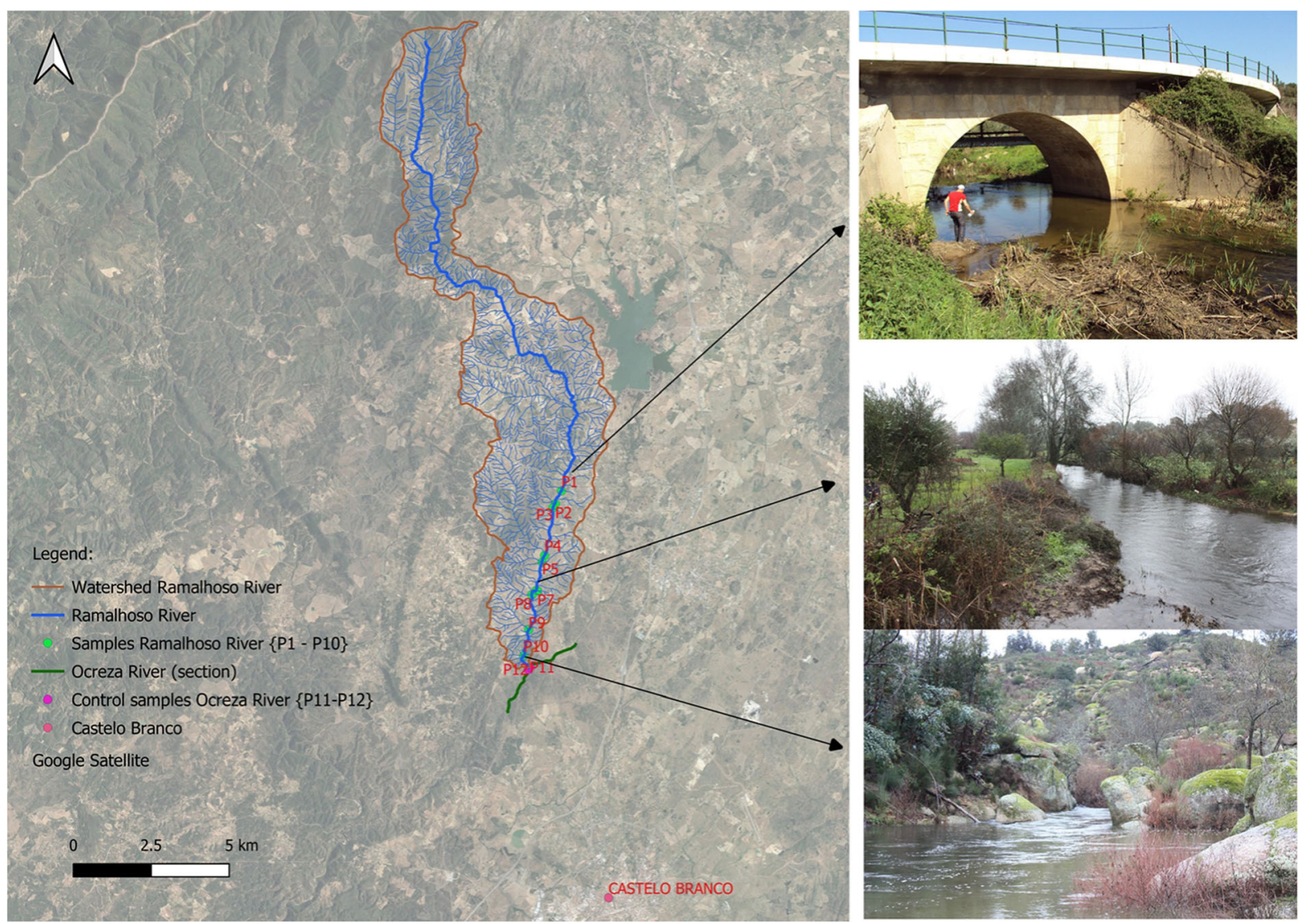

Fig. 2 Water sampling campaigns

The flow $(Q)$ measurement was made using the empirical field approach section-velocity method. This method consists of measuring the following: (1) the area of a cross-section of the watercourse (A) and (2) the flow's average speed through the section $(V)$. Since the depth of the river, in the selected cross-section, is variable, it was divided

Table 1 Laboratory parameter protocol for water quality determination

\begin{tabular}{ll}
\hline Water parameter & Analytical methods \\
\hline Total suspended solids & $\begin{array}{c}\text { PAFQ09 based on norm SMEWW } \\
2540 \mathrm{D}\end{array}$ \\
$\begin{array}{l}\text { Microbiological } \\
\text { parameters }\end{array}$ & PAB11 based on norm SMEWW \\
$\mathrm{BOD}_{5}$ & Manometric method \\
DO and COD & Volumetric precipitation \\
$\mathrm{N}_{\text {total }}$ & Computed \\
$\mathrm{P}_{\text {total }}$ & Molecular absorption spectrometry \\
\hline
\end{tabular}

into equal sections, and depth $(h)$ was measured for each of the considered parts (Fig. 3).

The flow's average speed $(V)$ was determined by registering the time a floating device took to go through a previously defined distance. The flow for each section $\left(Q_{i}\right)$ was determined $\left(Q_{i}=A_{i} * V_{i}\right)$ and the total flow obtained summing the values referring to each part $\left(\Sigma \boldsymbol{Q}_{i}\right)$. The procedure was repeated three times for each section, and the correspondent average was used for the final flow rate computation.

Dissolved oxygen (DO), biochemical oxygen demand $\left(\mathrm{BOD}_{5}\right)$, and total suspended solids (TSS) were used as indicators of organic matter and as parameters to assess water contamination and, therefore, as key attributes in the subsequent modeling procedure. Secondary intakes were identified, and water samples were taken downstream at approximately the same distances. QUAL2Kw is a modeling system for TMDL's - total maximum daily local — which can be translated as a maximum daily total load. The system determines the maximum quantity of pollutant load that a water line can 


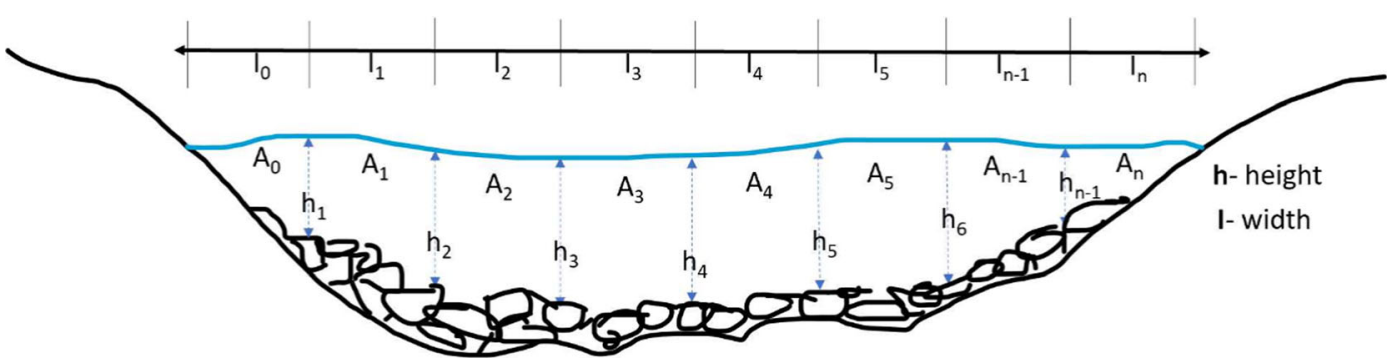

Fig. 3 Schematic field approach to estimate water flow

receive and still comply with the standards of water quality. Mathematical models of this type are used extensively for water quality planning and management aiming to predict variations in water quality that may occur in response to an increasing pollutant load. QUAL2Kw is based on ordinary differential equations for river systems unidimensional and constant flow, which can be used to simulate the behavior of several water quality indicators and parameters (Fan et al., 2009; Pelletier et al., 2006; Xiaobo et al., 2008). The

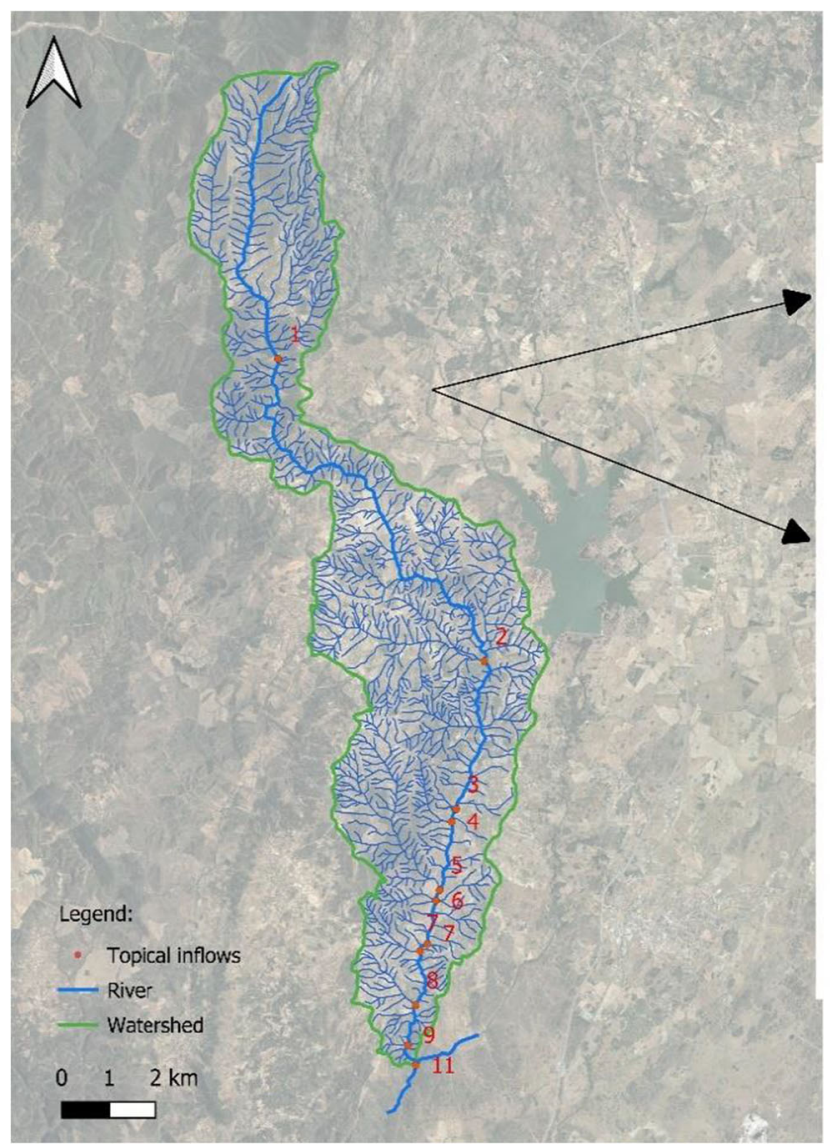

Fig. 4 Ramalhoso River segmentation model includes a PIKAIA genetic algorithm to calibrate the kinetic rates of parameters, optimizing the values by comparing predicted and observed data. This optimization is automatically determined by the square root of the mean of the errors (RMSE), the difference between the expected values and the observed values, in which a better-fit result in an application of the model when compared to the data observed (Xiaobo et al., 2008).

The model considers the entire length of the waterline with hydraulic characteristics constant in all stretches,

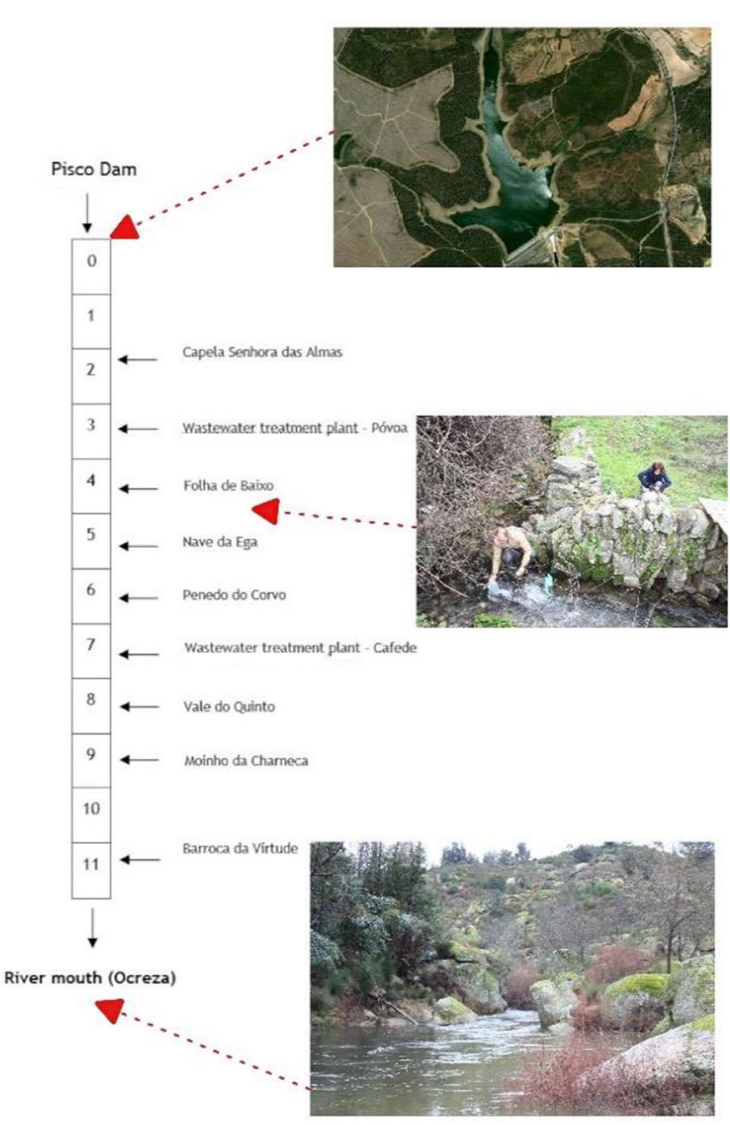


such as the slope of the margins and the width of the bed. The Ramalhoso River was divided into eleven segments (sections) with less than $1.50 \mathrm{~km}$ in length. Regarding the longitudinal slope, the water line varies between 0.0012 at the mouth and 0.11 at its source. The monitoring sampling points are located at the southern limit of each segment (Fig. 4).

For model calibration, the QUAL2Kw software provides manual or automatic calibration, using an internal genetic algorithm that calibrates the model automatically based on multiple stoichiometric and constant rates specified (Xiaobo et al., 2008). Calibration is a process that allows for an optimized adjustment between the observed and predicted values. For this survey, automatic calibration was used for the January, April, and June campaigns.

The calibration process aims to select several situations in which the input values for the selected variables in the model are known. The parameter input values allow the model to reproduce the output values as described by Xiaobo et al. (2008).

To guarantee the robustness of the parameter estimates, it is necessary to calibrate the model for various situations, representing the variety of scenarios that the model will have to simulate. The greater and more diverse the number of situations available to calibrate the model, the greater the user confidence in the results predicted by the model (Fan et al., 2009; Pelletier et al., 2006; Xiaobo et al., 2008).

In the present survey, parameters were assigned to the model, to reproduce the values observed in ten sampling points in rainy conditions (January), temperate conditions (April), and dry conditions (June). The parameters introduced in the model were as follows: temperature $\left({ }^{\circ} \mathrm{C}\right)$; electrical conductivity $(\mu \mathrm{S} / \mathrm{cm})$; total suspended solids $(\mathrm{mg} / \mathrm{L})$; dissolved oxygen $(\mathrm{mg} / \mathrm{L})$; $\mathrm{BOD}_{5}\left(\mathrm{mg} \mathrm{O}_{2} / \mathrm{L}\right) ; \mathrm{P}_{\text {total }}(\mu \mathrm{g} \mathrm{P} / \mathrm{L}) ; \mathrm{N}_{\text {total }}(\mu \mathrm{g} \mathrm{N} / \mathrm{L}) ; \mathrm{mi}-$ crobiological parameters (UFC/100 mL); and $\mathrm{pH}$ (Sörensen scale).

\section{Results}

The obtained physico-chemical and microbiological parameters of water samples are presented in Table 2.

The analyzed variables were statistically evaluated aiming to stress their space-time variation (Fig. 5). It is possible to identify the samples $\mathrm{P} 3$ and $\mathrm{P} 7$ as the ones with the highest $\mathrm{BOD}_{5}$ and total suspended solids (TSS)

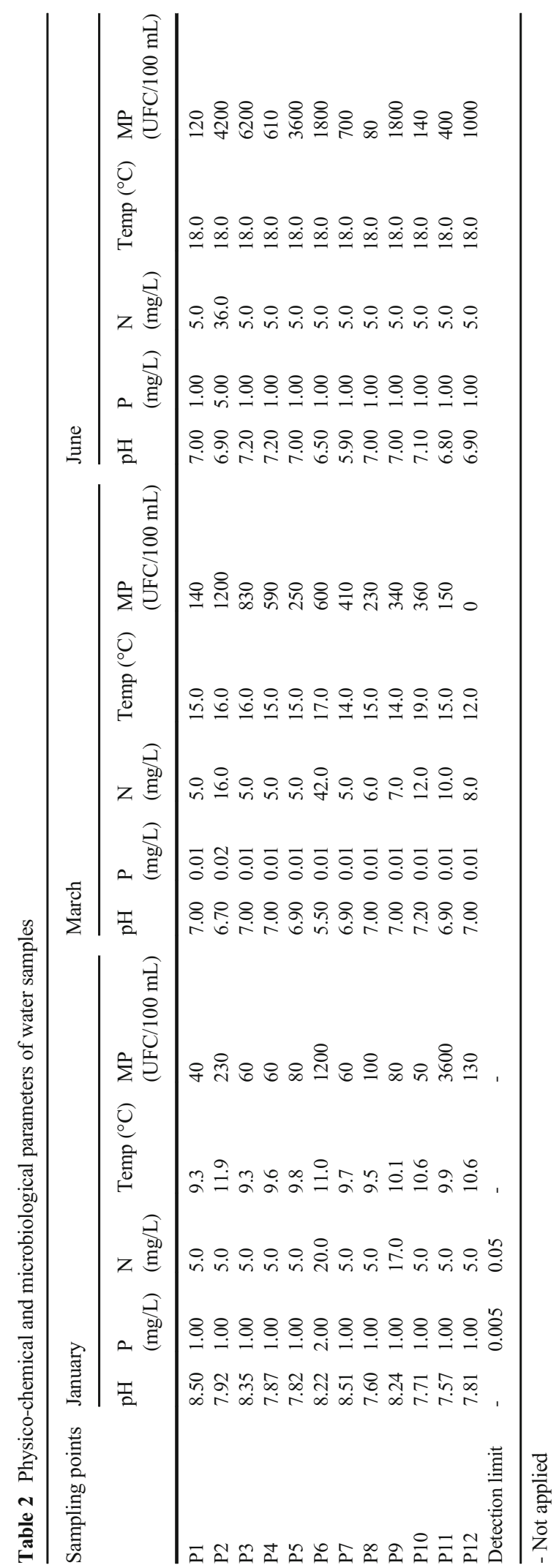




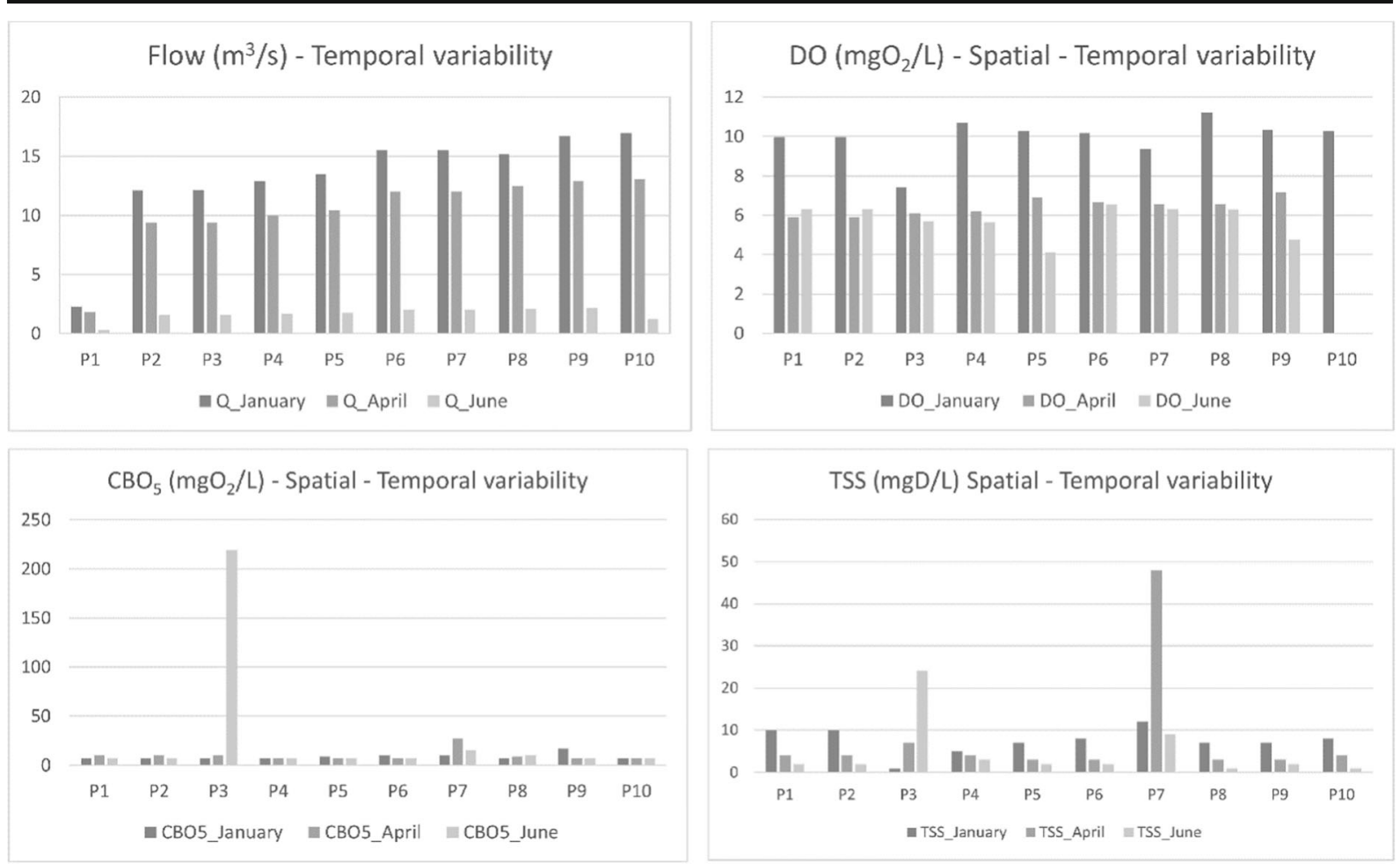

Fig. 5 Space-time variability of water for flow; dissolved oxygen (DO); biochemical oxygen demand (BOD $)$, and total suspended solids (TSS)

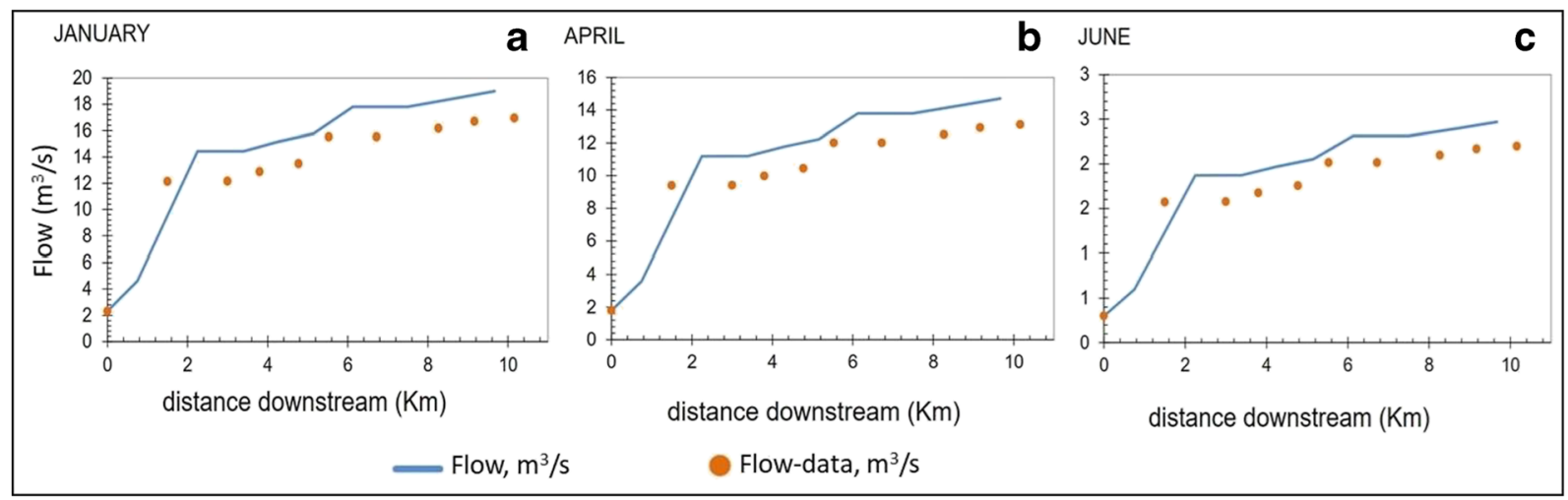

Fig. 6 Flow simulation: a January; b April; and c June

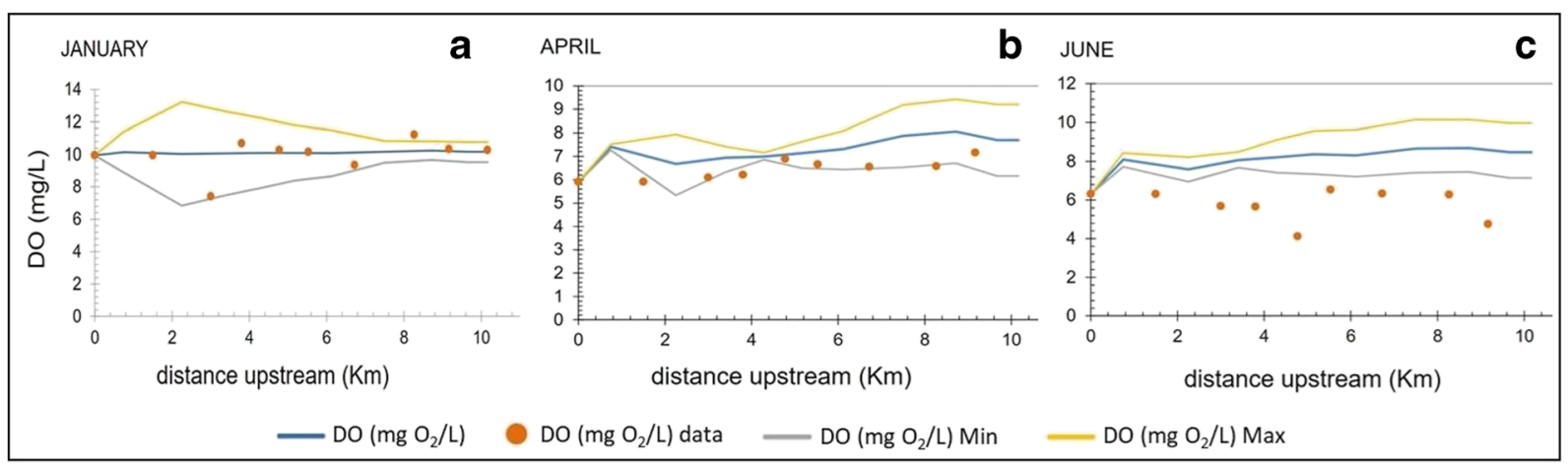

Fig. 7 Dissolved oxygen simulation: a January; b April; and c June 


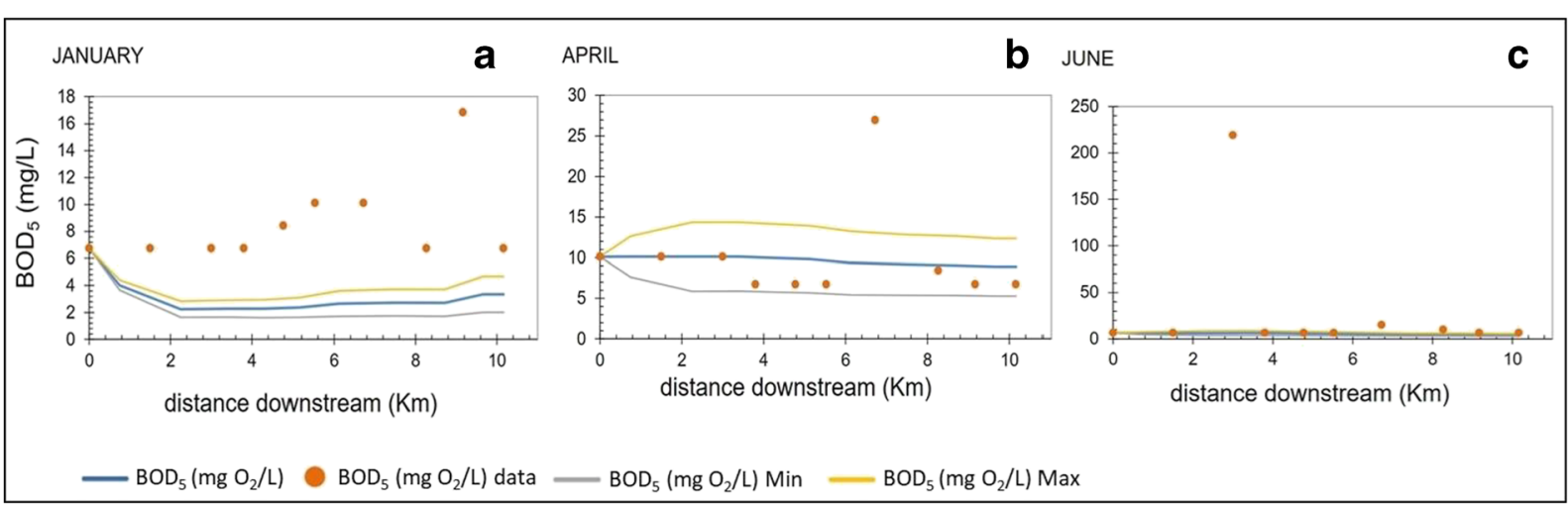

Fig. 8 Biochemical oxygen demand $\left(\mathrm{BOD}_{5}\right)$ simulation: a January; b April; and c June

which could be related to the addition of diffuse contributions associated with agriculture seasonality. However, it is possible to observe a general decrease, for all three campaigns, downstream the river which indicates a river's fair self-depuration (Table 2).

An overall analysis makes it possible to say that the results of the calibration of the different parameters were acceptable. In future work, field rates and kinetic coefficients are key covariates for improved calibration and, as a result, improved quality of the QUAL2Kw model's suitability.

\subsection{Flow Calibration}

The flow calibration reveals a fair fit for all three measured seasons and, this way, allowed to validate the adopted field measurement technique. It is worth noticing that the spatial distribution pattern is very similar along the hydrological year with a maximum flow variation between $2 \mathrm{~m}^{3} \mathrm{~s}^{-1}$ in June and $18 \mathrm{~m}^{3} \mathrm{~s}^{-1}$ in January (Fig. 6).

\subsection{Dissolved Oxygen Calibration}

The calibration of dissolved oxygen for the studied periods varies with the influences received along the river (Fig. 7). The best calibration was achieved in the rainy season (January) because of higher flows. Generally, it can be concluded that the Ramalhoso River has a normal oxygen level and adequate surface water quality.

\subsection{Biochemical Oxygen Demand Calibration}

The results of the biochemical oxygen demand $\left(\mathrm{BOD}_{5}\right)$ calibration show the systematic presence of an outlier, respectively, sample P9, collected in January, sample P7, collected in April, and sample P3, collected in June (Fig. 8). Considering the location and observed flow rates, it is possible to consider these abnormal values due to agricultural diffuse contributions. Sample P3 was collected near the Póvoa wastewater plant's discharge in June, possibly indicating a deficient water

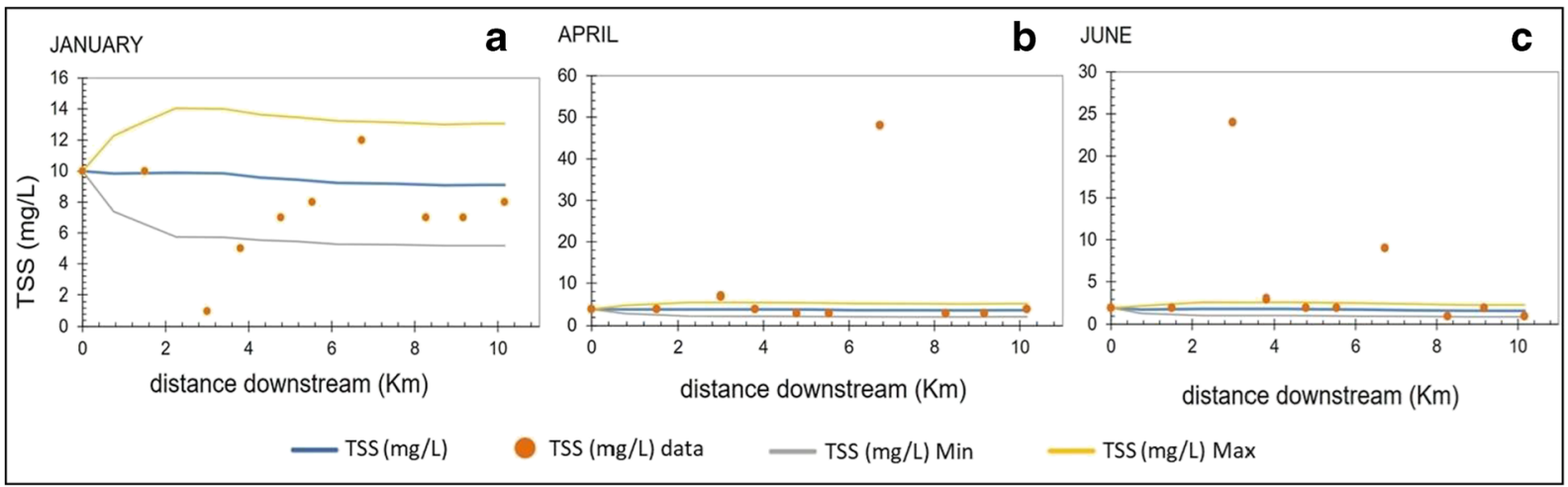

Fig. 9 Total suspended solid simulation: a January; b April; and c June 
treatment, in low flow conditions, during the dry season (Fig. 8).

\subsection{Total Suspended Solid Calibration}

The total suspended solid model's best fit corresponds to January. The calibration for April is not acceptable showing the need for additional validation data. It is important to stress that the sample point P7 is an outlier, in both January and June campaigns, and a possible explanation may be related to diffuse contributions associated with agricultural activities. Water sample point P3 (Póvoa's Wastewater Treatment Plant) is an outlier during the dry season, June, which points out to possible deficient wastewater treatment (Fig. 9).

\section{Discussion}

The studied parameters were calibrated. In terms of specific parameter analysis, more emphasis will be given to dissolved oxygen and biological oxygen demand. The dissolved oxygen parameter is important to control as it affects the reactions in the hyporheic zone and is related to other coexistent water parameters, namely nitrogen, organic matter, and chlorophyll a. The simulated values remain between a minimum of $\pm 6 \mathrm{mg} / \mathrm{L}$ in June and $\pm 10 \mathrm{mg} / \mathrm{L}$ in January, complying with the values provided for agricultural irrigation in the Portuguese water legislation. For the $\mathrm{BOD}_{5}$, the values follow the trend of an increase following a wastewater plant discharge, which started to decline after the last discharge. The value of water $\mathrm{pH}$ is quite satisfactory for surface waters, being higher in January (8.3-8.5) and lower in April (6.8-7.0). There is a decrease in water $\mathrm{pH}$ from upstream to downstream, influenced by the sewage discharges and returning to the balance close to the mouth.

The QUAL2Kw calibration for Ramalhoso River water quality showed some limitations, namely, (1) the reduced sampling field data in each simulated periodin the sense that minimizing the uncertainties in the values introduced as a reference would be convenient to have daily dataset series or a series of several years for the same month; (2) experimental measurements of flow rates - flow values for point calibration were estimated using the semi-empirical formula of Giandotti; and (3) identification of diffuse polluting sources - the mathematical formulation for the hydraulic system description was based on the Gauckler-Manning-Strickler equation, assuming the same slope along with the river's longitudinal profile and the same coefficient (Manning = 0.040); however, the river shows some heterogeneity.

\section{Conclusions}

The Ramalhoso River water quality indicates pollution issues essentially associated with organic contamination $\left(\mathrm{BOD}_{5}\right.$ and TSS), namely due to sewage discharge. The Qual2kw model's calibration is acceptable for most parameters and, therefore, can forecast the Ramalhoso River water's quality throughout the hydrological year. Considering the obtained results and the model's potential as a tool to support planning and management, in future work, corrective measures will be taken to improve Ramalhoso River water quality aiming to rebalance the fluvial ecosystem, allowing an effective selfpurification with the reduction of the organic contamination. For immediate mitigation, it is recommended that the wastewater plant treatment system increase the flow during summer, by storing water in the rainy season at the Pisco dam, which will improve water quality. The parameters, flow rate, speed, and depth of the channel must be determined in situ to obtain a calibration based on real values over literature estimated ones.

Author Contribution Conceptualization: Gregory Pelletier; Data curation: Pedro Almeida Teresa Albuquerque and Ana Ferreira; Formal analysis: Pedro Almeida, Teresa Albuquerque and Gregory Pelletier; Funding acquisition: Teresa Albuquerque and Margarida Antunes; Investigation: Pedro Almeida, Teresa Albuquerque, Ana Ferreira, and Margarida Antunes; Methodology: Teresa Albuquerque, Margarida Antunes, and Gregory Pelletier; Software: Gregory Pelletier; Supervision, Teresa Albuquerque, and Ana Ferreira; Validation: Pedro Almeida; Visualization: Pedro Almeida; Writing — original draft: Teresa Albuquerque; Writing - review and editing: Pedro Almeida Margarida Antunes and Ana Ferreira

Funding This research was funded by Águas do Centro Enterprise and by the Institute of Earth Sciences (ICT), under contracts UID/GEO/04683/2013 with FCT (Portuguese Science and Technology Foundation).

\section{References}

Albuquerque, M. T. D., Antunes, I. M. H. R., Oliveira, N. P., \& Pelletier, G. (2019). Impact of sewage effluent discharges 
prediction using QUAL2Kw in a sensitive protected area: Portugal. SN Applied Sciences, 1, 1167. https://doi. org/10.1007/s42452-019-1095-y.

Antunes, I. M. H. R., Albuquerque, M. T. D., Oliveira, S. F., \& Sánz, G. L. (2018). Predictive scenarios for surface water quality simulation-A watershed case study. CATENA, 170, 283-289. https://doi.org/10.1016/j.catena.2018.06.021.

Aubertheau, E., Stalder, T., Mondamert, L., Ploy, M. C., Dagot, C., \& Labanowski, J. (2017). Impact of wastewater treatment plant discharge on the contamination of river biofilms by pharmaceuticals and antibiotic resistance. Science of the Total Environment, 579, 1387-1398. https://doi. org/10.1016/j.scitotenv.2016.11.136.

Delhomme, O., Rib, E., \& Millet, M. (2008). Polycyclic aromatic hydrocarbons analyzed in rainwater collected on two sites in East France (Strasbourg and Erstein). Polycyclic Aromatic Hydrocarbon, France, 28, 4-5.

DiGiano, F., \& Grayman, W. M. (2014). Can we better protect vulnerable water supplies? Journal of American Water Works Association, 106, 28. https://doi.org/10.5942 /jawwa.2014.106.0067.

European Union. (1991). Council Directive 1991/271/EEC on Urban waste water treatment. Official Journal of the European Union, 1991, 135/40-135/52.

Fan, C., Ko, C. H., \& Wang, W. S. (2009). An innovative modeling approach using Qual2K and HEC-RAS integration to assess the impact of tidal effect on river water quality simulation. Journal of Environmental Management, 90(5), 18241832. https://doi.org/10.1016/j.jenvman.2008.11.011.

Farhadian, M., Bozorg-Haddad, O., Pazoki, M., \& Loáiciga, H. A. (2019). Minimal adverse impact of discharging polluted effluents to rivers with selective locations. Sustainable Cities and Society, 46, 101394. https://doi.org/10.1016/j. scs.2018.12.022.

Gonzalo, C., \& Camargo, J. A. (2013). The impact of an industrial effluent on the water quality, submersed macrophytes and benthic macroinvertebrates in a dammed river of central Spain. Chemosphere, 93(6), 1117-1124. https://doi. org/10.1016/j.chemosphere.2013.06.032.

Grabiç, J., Bezdan, A., Benka, P., \& Salvai, A. (2011). Spreading and transformation of nutrients in the Reacg of the BecejBogojeco Canal, Serbia. Carparth. Journal of Earth and Environmental Sciences, 6(1), 277-284.

Henderson-Sellers, B. (1991). Water quality modeling: decision support techniques for lakes and reservoirs. CRC Press, London, vol 4 (p. 344). Boston: CRC Press.

Hilario Garcia, A. L., Matzenbacher, C. A., Santos, M. S., Prado, L., Picada, J. N., Premoli, S. M., Correa, D. S., Niekraszewicz, L., Dias, J. F., Grivicich, I., \& da Silva, J. (2017). Genotoxicity induced by water and sediment samples from a river under the influence of brewery effluent. Chemosphere, 169, 239-248. https://doi.org/10.1016/j. chemosphere.2016.11.081.

Jeznach, L. C., Jones, C., Matthews, T., Tobiason, J. E., \& Ahlfeld, D. P. (2016). A framework for modeling contaminant impacts on reservoir water quality. Journal of
Hydrology, 537, 322-333. https://doi.org/10.1016 /jhydrol.2016.03.041.

Khwairakpam, E., Khosa, R., Gosain, A., et al. (2019). Monitoring and modelling water quality of Loktak Lake catchment. SN Applied Sciences, 1, 491. https://doi.org/10.1007/s42452019-0517-1.

Li, D., Sharp, J. O., \& Drewes, J. E. (2016). Influence of wastewater discharge on the metabolic potential of the microbiological community in river sediments. Microbial Ecology, 71, 78-86. https://doi.org/10.1007/s00248-015-0680-x.

Lin, C. E., Kao, C. M., Jou, C. J., Lai, Y. C., Wu, C. Y., \& Liang, S. H. (2010). Preliminary identification of watershed management strategies for the Houjing River in Taiwan. Water Science and Technology, 62(7), 1667-1675. https://doi. org/10.2166/wst.2010.460.

Pelletier, G. J., Chapra, S. C., \& Tao, H. (2006). QUAL2 Kw-A framework for modelling water quality in streams and rivers using a genetic algorithm for calibration. Environmental Modelling and Software, 21(3), 419-425. https://doi. org/10.1016/j.envsoft.2005.07.002.

Sharma, D., \& Kansal, A. (2013). Assessment of river quality models: A review. Reviews in Environmental Science and Biotechnology, 12, 285-311. https://doi.org/10.1007 /s11157-012-9285.

Sousa, J. C. G., Ribeiro, A. R., Barbosa, M. O., Pereira, F. R., \& Silva, A. M. T. (2018). A review on environmental monitoring of water organic pollutants identified by EU guidelines. Journal of Hazardous Materials, 344, 146-162. https://doi. org/10.1016/j.jhazmat.2017.09.058.

Tiedeken, E. J., Tahar, A., McHugh, B., \& Rowan, N. J. (2017). Monitoring, sources, receptors, and control measures for three European Union watch list substances of emerging concern in receiving waters-A 20-year systematic review. Science of the Total Environment, 574, 1140-1163. https://doi.org/10.1016/j.scitotenv.2016.09.084.

Tillaart, S. P. M., Booij, M. J., \& Krol, M. S. (2013). Impact of uncertainties in discharge determination on the parameter estimation and performance of a hydrological model. Journal of Hydrology, 44(3), 454-466. https://doi. org/10.2166/nh.2012.147.

Vystavna, Y., Frkova, Z., Celle-Jeanton, H., Diadin, D., Huneau, F., Steinmann, M., Crini, N., \& Loup, C. (2018). Priority substances and emerging pollutants in urban rivers in Ukraine: occurrence, fluxes and loading to transboundary European Union watersheds. Science of the Total Environment, 637-638, 1358-1362. https://doi.org/10.1016 /j.scitotenv.2018.05.095.

Whitehead, P. G., Futter, M. N., Comber, S., Butterfield, D., Pope, L., Willows, R., \& Burgess, C. (2015). Modelling impacts of seasonal wastewater treatment plant effluent permits and biosolid substitution for phosphorus management in catchments and river systems. Journal of Hydrology, 46(3), 313324. https://doi.org/10.2166/nh.2014.100.

Xiao, S., Hu, S., Zhang, Y., Zhao, X., \& Pan, W. (2018). Influence of sewage treatment plant effluent discharge into multipurpose river on its water quality: A quantitative health risk 
assessment of Cryptosporidium and Giardia. Environmental Pollution, 233, 797-805.

Xiaobo, F., Jianying, Z., Yingxu, C., \& Xiangyang, X. (2008). QUAL2K model used in the water quality assessment of Qiantang River, China. Water Environment Research, 80(11), 2125-2133.

Zafar, S., Kahan, A., Ullah, H., Khan, M. S., Khan, I., Hammed, A., Rehman, S. U., \& Yasmeen, G. (2017). Risk assessment of Giardia from a full scale MBR sewage treatment plant caused by membrane integrity failure. Journal of Environmental Sciences, 30, 252-258. https://doi. org/10.1016/j.jes.2014.09.033.

Publisher's Note Springer Nature remains neutral with regard to jurisdictional claims in published maps and institutional affiliations. 